\title{
A Heliocentric Journey into Germany's Great Depression
}

\author{
Mark Weder \\ Department of Economics \\ Humboldt University Berlin \\ Spandauer 1 \\ 10178 Berlin \\ and \\ CEPR
}

February 20, 2004

\begin{abstract}
The paper finds empirical evidence on the ripple effect of sunspots on the interwar German economy. It identifies a sequence of negative shocks to expectations for the 1927 to 1932 period. The artificial economy predicts the 1928-1932 depression and a long boom from 1933 onwards. Overall, a tangible fraction of interwar output volatility is attributed for by sunspots.
\end{abstract}

\section{Introduction}

Over the past decade the literature on indeterminacy in macroeconomics has moved from slight obscurity into the spotlight by demonstrating that otherwise standard models can exhibit multiple equilibria, and, moreover, that nonfundamental shocks (a.k.a. sunspots or animal spirits) can generate dynamics that resemble observed aggregate fluctuations. ${ }^{1}$ For sunspots to be an accepted explanation for business cycles, however, it is vital that the implications be supported by empirical evidence. The present paper offers such evidence and it does so by looking at one of the most troubling of cyclical episodes: the Great Depression in Germany.

\footnotetext{
${ }^{1}$ Benhabib and Farmer (1999) provides a superb review of sunspot models.
} 


\subsection{Map of the paper}

The paper unfolds in four parts. The first part assigns theory. Sunspot models are distinguished from other models in that they find the original source of economic fluctuations in shocks to expectations. The chosen theoretical model here is a non-monetary, fully specified dynamic general equilibrium model with increasing returns of a magnitude consistent with empirical evidence. The size of scale economies is significant enough to give rise to equilibria which are indeterminate; hence non-fundamental expectations matter.

In the second part of the paper, the artificial economy is exploited to derive the sunspot shocks. Data will be filtered through the model to ferret out residuals. Specifically, sunspots are uncovered by sifting out the part of the model that is not explained by fundamentals so as to reflect changes in extrinsic uncertainty. The paper finds a sequence of pernicious sunspot shocks that seeped into the German economy from 1927:IV to 1932:III. This roughly coincides with the economic cycle: the German business cycle peaked in the first quarter of 1928 and passed its trough in the third quarter of 1932 (see Figure 1).

The effects of the estimated sunspot innovations will be traced in the third part of the paper. I check the forecasting ability of sunspots and test the predictive power of the model, i.e. the empirical shocks will be fed back into the model. I find that sunspot impulses can account for a significant portion of the interwar cycle in Germany. The fourth part probes various dimensions of the results' robustness.

The paper thus provides new support to Temin's (1971) interpretation of the German Depression. Temin stresses a fall in domestic demand, however, he leaves unexplained the ultimate cause of the plunge:

"Sales, unfilled orders, expectations; these are the items we are told influence investment. [...] To elucidate the nature of this change, attention must be shifted from the international economy to the domestic and from supply considerations to demand." [Temin, 1971, p. 248]

The findings here suggest that it was sunspots which had a ripple effect on aggregate demand and, consequently, on the German economy.

\subsection{Methodology and related work}

The paper is related to recent attempts that employ theoretical models in a beeline to trace the sources of economic fluctuations (see for example Chari, Kehoe and McGrattan's, 2002, accounting framework). It also resembles 


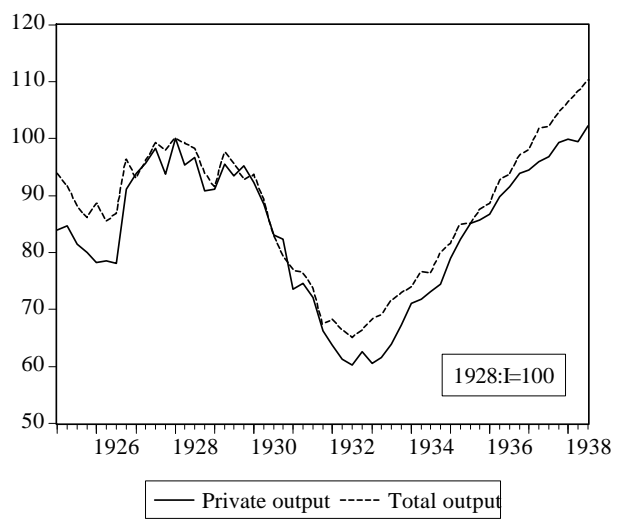

Figure 1: Linearly detrended per capita outputs. Private output is sum of the private sector's consumption and investment expenditures.

work that computes historical sunspots (for example Harrison and Weder, 2001). Within a dynamic general equilibrium framework, the current paper builds on and modifies a method originally developed by Sheffrin and Salyer (1998) for post-war U.S. data. In a nutshell, Sheffrin and Salyer uncover sunspots by using financial markets in conjunction with the error term of the artificial economy's consumption equation. The procedure applied in the present paper borrows from Salyer and Sheffrin's yet several important differences distinguish their work from mine: (i) I do not employ financial markets, (ii) the underlying theoretical model is different - they use a version of Farmer and Guo (1994) which requires unrealistically large increasing returns to scale - (iii) sunspots are sifted out from the model equation's residuals in different ways, and (iv) the forecasting power of shocks to expectations is determined. Furthermore, I show that alternative methods of sunspots estimation - the Salyer and Sheffrin procedure as well as the one which was developed by Harrison and Weder (2001) - predict very similar sequences of shocks.

To my knowledge, Fisher and Hornstein (2002) and Weder (2003) are the only other approaches which attempt to explain the Great Depression in Germany using dynamic general equilibrium theory. Both find a deterioration in total factor productivity which accounts for a substantial decline in economic activity - yet both claim that a complete explanation requires many more inputs such as fiscal shocks and labor market distortions (in the case of Fisher and Hornstein) or taste shocks (in Weder's case). Contrary to these mentioned papers which rely on theoretical inclusiveness in the hope of drawing together varying approaches to show how these contribute to a 
more complete explanation, the paper here pursues a monocausal approach. This does not rule out other factors such as the above mentioned. However, the monocausal strategy applied here allows the effects of expectations to be isolated.

Another conceptual issue in this work pertains to the notion of equilibrium economics. Equilibrium business cycle models - such as the one championed here - banish the notion of involuntary unemployment essentially because of its unsound distinction and as an intricate concept. Therefore, business cycles are not interpreted as deviations from equilibrium but decoded as fluctuations of the equilibrium itself. Consequently, those out of work must have chosen leisure over work, however, the equilibrium concept does not presume that the unemployed like depressions:

"Of course, the hypothesis of a cleared labor market carries with it no such suggestion, any more than the observation that people go hungry in cleared food markets suggest that people enjoy hunger." [Lucas, 1977, p. 226].

More importantly, equilibria do not necessitate Pareto-efficiency: the artificial economy that will be outlined shortly is interspersed with imperfect markets and any realized equilibrium represents a flaw in the economy that a rearrangement of resources could correct at no cost to anyone. In short, the labor market is modelled as if in equilibrium, therefore, the controversy is not whether unemployment is involuntary but instead whether the level of employment is efficient. It clearly isn't.

\section{The artificial economy}

This Section presents the theoretical model, discusses the calibration and reports on qualitative dynamics. The economy is a standard dynamic general equilibrium model with variable capital utilization, internal scale economies and monopolistic competition. ${ }^{2}$

The economy consists of two sectors. The final goods sector is perfectly competitive. Final goods production assembles distinct intermediate inputs $y_{i, t}$ with the constant returns to scale production function

$$
y_{t}=\left(\int_{0}^{1} y_{i, t}^{v} d i\right)^{1 / v} \quad 0<v<1
$$

\footnotetext{
${ }^{2}$ The models by Greenwood, Hercowitz and Huffman (1988), Farmer and Guo (1994) and Wen (1998) - to which my model is most closely related - feature similar attributes.
} 
where $i \in[0,1]$. The conditional demand for $y_{i, t}$ can be derived as

$$
y_{i, t}=\left(\frac{p_{i, t}}{\mathbf{p}_{t}}\right)^{\frac{1}{v-1}} y_{t}, \quad \mathbf{p}_{t} \equiv\left(\int_{0}^{1} p_{i, t}^{\frac{v}{v-1}} d i\right)^{\frac{v-1}{v}} .
$$

Here, $p_{i, t}$ is firm's $i$ price and $\mathbf{p}_{t}$ is the exact price index. Monopolistic competitors produce intermediate products and have access to an increasing returns to scale technology given by

$$
y_{i, t}=z_{t}\left(u_{t} k_{i, t}\right)^{\alpha} l_{i, t}^{\beta} \quad \alpha+\beta>1 .
$$

Firms rent the services from labor, $l_{i, t}$, and capital, $k_{i, t}$, from the household at the competitive rental rates $w_{t}$ and $r_{t}$. The household decides on the index of the use of capital, $u_{t}$. It is taken as given by the firms. $z_{t}$ is the state of technological knowledge which is determined outside the model. It follows the first-order autoregressive process

$$
\ln z_{t}=(1-\zeta) \ln z+\zeta \ln z_{t-1}+\varepsilon_{t} \quad 0<\zeta<1 .
$$

The shocks to technology, $\varepsilon_{t}$, are uncorrelated at all leads and lags and uncorrelated with $z_{t-j} \nabla j>0$. They are the part of $z_{t}$ that cannot be predicted based on past values of the variables of the model. Each monopolistic competitor's profit maximization is given by the static problem

$$
\max _{l_{i, t}, k_{i, t}} p_{i, t} y_{i, t}-w_{t} l_{i, t}-r_{t} k_{i, t} \quad \text { s.t. (2) and (3) }
$$

where the maximand is concave in inputs whenever $(\alpha+\beta) v$ is less or equal to one. In fact, I will restrict $(\alpha+\beta) v=1$ which implies zero average pure profits. The assumption is on congenial terms with data reported by Sweezy (1940). ${ }^{3}$ The factor demands of firm $i$ are

$$
w_{t}=\beta v p_{i, t} z_{t}\left(u_{t} k_{i, t}\right)^{\alpha} l_{i, t}^{\beta-1} \quad \text { and } \quad r_{t}=\alpha v p_{i, t} z_{t}\left(u_{t} k_{i, t}\right)^{\alpha-1} l_{i, t}^{\beta} .
$$

that is, firms are renting effective capital units, i.e. $u_{t} k_{t}$. The reason is the following. Technology displays a nonconvexity if the usual commodity point is employed: an alternative commodity is needed. My approach is to assume that firms demand effective capital units. Phrased alternatively, from the firm's point of view, output can be increased by running existing machines more intensely or by put into operation additional machines. The firms do not care how the increase is realized; the decision is made by the household who own the capital stock and who can decide on the utilization rate.

\footnotetext{
${ }^{3}$ Splitting up the capital income into rental and pure profit income, for example, would change the model insofar as to make it even easier to obtain indeterminacy.
} 
All intertemporal decisions are administered by the household sector. Households supply labor to and purchase output from the firms. The stand-in household's preferences are ordered by

$$
U=E_{0} \sum_{t=0}^{\infty} \rho^{t} u\left(c_{t}, 1-l_{t}\right) \quad 0<\rho<1
$$

where $c_{t}$ and $\rho$ stand for consumption and the discount factor. The period utility function is assumed to have the form

$$
u\left(c_{t}, 1-l_{t}\right)=\eta \log c_{t}-(1-\eta) l_{t} \quad 0<\eta<1 .
$$

Logarithmic utility ensures the existence of a balanced growth path. The fact that labor, $l_{t}$, enters linearly in the utility function follows the assumption that labor is indivisible, utility is separable in consumption and in leisure and agents trade employment lotteries. $E_{t}$ is the expectations operator, conditional on all information available in periods $t$ and earlier. The capital accumulation equation

$$
k_{t+1}=\left(1-\delta_{t}\right) k_{t}+w_{t} l_{t}+r_{t} k_{t}+\Pi_{t}-c_{t}
$$

is a standard one except for the variable depreciation rate, $\delta_{t}$. Depreciation is an increasing convex function of utilization

$$
\delta_{t}=\frac{1}{\theta} u_{t}^{\theta} \quad \theta>1 .
$$

Higher utilization causes faster depreciation because of wear and tear on the capital stock. $\Pi_{t}$ represents pure profit income arising from the presence of market power. Factor prices (and profit income) are taken as given by the household. The maximization of (5) subject to (6) yields the first order conditions

$$
\begin{gathered}
\frac{\eta}{1-\eta}=\frac{w_{t}}{c_{t}} \\
\frac{1}{c_{t}}=E_{t} \frac{\rho}{c_{t+1}}\left(r_{t+1} u_{t+1}+1-\frac{1}{\theta} u_{t+1}^{\theta}\right)
\end{gathered}
$$

and

$$
u_{t}^{\theta}=r_{t}
$$


In addition, the budget constraint

$$
k_{t+1}=\left(1-\frac{1}{\theta} u_{t}^{\theta}\right) k_{t}+y_{t}-c_{t}
$$

and the usual transversality condition - given the initial stock of capital, $k(0)>0$ - must hold. Equation (7) describes the consumption-leisure tradeoff, (8) is the intertemporal Euler equation. (9) characterizes the efficient level of capital utilization. It states that capital should be utilized at a rate which sets the marginal user costs equal to the marginal benefit of capital services.

In symmetric equilibrium, we have $k_{i, t}=k_{t}, l_{i, t}=l_{t}, y_{i, t}=y_{t}$, and $p_{i, t}=p_{t}=1$. The last equality comes from the zero profits condition in the final goods sector with final goods being the numeraire. The first-order conditions with respect to capital utilization and investment become

$$
u_{t}^{\theta}=\alpha v \frac{y_{t}}{k_{t}}
$$

and

$$
\frac{1}{c_{t}}=E_{t} \frac{\rho}{c_{t+1}}\left(\alpha v \frac{y_{t+t}}{k_{t+1}}+1-\frac{1}{\theta} u_{t+1}^{\theta}\right)
$$

and, consequently, the commodity point selection does not change the usual forms of these Euler equations. ${ }^{4}$

Next, I calibrate the model using parameter values that mimic certain ratios of the actual German economy that are more or less constant. Time evolves in discrete units and periods are specified to be one quarter long. Significant market power is widely reported for interwar Germany. For example, Kellenbenz (1981) estimates the rise of cartels from 233 to 1539 in the period from 1905 to 1925 . To offer an idea of the extent of market power, Bloch (1932) compares price indices of raw material and semifinished products arranged by commodities for domestic and foreign consumption. Over the 1929 to 1932 period, the domestic price level was about 30 percent above the world price level. A high degree of de facto cartelization was also widespread in the agricultural sector due to the political influence of East Elbian Junkers. In this respect, Kindleberger (1986) notes that the market power combined with import restrictions

"[...] raised German agricultural prices to Rm 2 billion above the level of world prices in 1932." [Kindleberger, 1986, p. 132]

\footnotetext{
${ }^{4}$ See for example Greenwood et al. (1998) or Wen (1998).
} 
No reliable estimate of markups for interwar Germany is available, however. Following recent evidence by Basu and Fernald (1997) and others on the United States, I assume that the average markup is 20 percent. This implies that $v=0.83$ so that the elasticity of substitution between varieties of intermediate goods is about 6 and, consequently, the returns to scale amount to 1.20. The capital share is 25 percent. The steady state rate of depreciation is 3 percent per annum. The discount factor, $\rho$, is set such that the steady state capital-output ratio is 4.18 which is the empirical observed value (for great ratios and depreciation rates see Ritschl, 2002b). The weight on utility, $\eta$, has no influence on equilibrium dynamics and is therefore not needed to be calibrated. Denoting steady state values with no time subscripts, the unique steady state is described by the set of equations

$$
\begin{aligned}
& \frac{1}{\rho}=\alpha v \frac{y}{k}+1-\delta \\
& \frac{1}{\rho}=1-\delta(1-\theta)
\end{aligned}
$$

and

$$
\delta=\frac{x}{k}=\frac{x}{y} \frac{y}{k}
$$

The conditions imply a value of 1.99 for the elasticity of depreciation with respect to utilization, $\theta$. The steady state investment share on output, $x / y$, is 17 percent.

I take a log-linear approximation to the equilibrium conditions to obtain the following dynamical system that describes the economy (see Appendix):

$$
\left(\begin{array}{c}
\widehat{c}_{t+1} \\
\widehat{k}_{t+1} \\
\widehat{z}_{t+1}
\end{array}\right)=\mathbf{M}\left(\begin{array}{c}
\widehat{c}_{t} \\
\widehat{k}_{t} \\
\widehat{z}_{t}
\end{array}\right)+\mathbf{W}\left(\begin{array}{c}
\omega_{t+1} \\
0 \\
\varepsilon_{t+1}
\end{array}\right)
$$

Hatted variables denote percent deviations from their steady-state values. $\mathbf{M}$ is the $3 \times 3$ Jacobian matrix of partial derivatives. The term $\omega_{t+1} \equiv E_{t} \widehat{c}_{t+1}-$ $\widehat{c}_{t+1}$ denotes the expectational error. Its role is as follows. Consumption is a non-predetermined variable whereas capital is predetermined. If exactly one eigenvalue of $\mathbf{M}$ is outside the unit circle, the model is unique (i.e. saddle-path stable); unless the extraneous random variable $\omega_{t+1}$ is removed, the economy would eventually violate the transversality conditions. With the presence of market power, however, the First Welfare Theorem does not hold. Accordingly, we do not have the guarantee that the equilibrium is unique. 
Indeterminacy of rational expectations requires that both eigenvalues of $\mathbf{M}$ are inside the unit circle. This situation implies that equilibria are possible in which fluctuations in economic activity may be driven by arbitrary and self-fulfilling changes in people's expectations. Rational expectations require that expectational errors be essentially random errors which are uncorrelated with the information obtained and processed: in a word, people make no systematic mistakes.

Sunspot cycles are generated in the model in the following manner. Let there be a pessimistic shock to expectations unrelated to any available fundamental data - the first step in a harmful sequence of events. In particular, people believe that the future income stream dwindles. The households respond by reducing today's consumption expenditures and by increasing the supply of labor. To understand the effect of the change in expectations on employment, one must regard that labor demand is unconventionally sloped given departures from constant returns. This can be seen by combining the symmetric equilibrium conditions

$$
u_{t}^{\theta}=\alpha v \frac{y_{t}}{k_{t}} \quad \text { and } \quad y_{t}=z_{t}\left(u_{t} k_{t}\right)^{\alpha} l_{t}^{\beta}
$$

which yield

$$
y_{t}=(\alpha v)^{\frac{\alpha}{\theta-\alpha}} z_{t}^{\frac{\theta}{\theta-\alpha}} k_{t}^{\frac{\alpha(\theta-1)}{\theta-\alpha}} l_{t}^{\frac{\beta \theta}{\theta-\alpha}} .
$$

Given Table 1's calibration, the effective labor-output elasticity

$$
\frac{\beta \theta}{\theta-\alpha}
$$

exceeds unity for markups (or, equivalently, increasing returns to scale) larger than 1.16: the reduced-form labor demand curve is upward sloping. Now, the sunspot-driven shift in labor supply reduces employment and investment today. Therefore, the future capital stock and output will be low and the initially pessimistic undercurrent about future income is self-fulfilled. This completes the circuit.

Bernanke and Parkinson (1991) propose a simple test that can be applied to check for the plausibility of increasing returns of the magnitude needed here. Given the lack of reliable disaggregated data, I look at the relation between movements in aggregate output and labor input (standard errors in parentheses):

$$
\begin{array}{lll}
\Delta \ln y_{t}^{d} & =\underset{(0.019)}{-0.014}+\underset{(0.139)}{1.010 \Delta \ln l_{L, t}^{d}+\underset{(0.002)}{0.006 t}} \quad \bar{R}^{2}=0.85, D . W .=1.40 \\
\Delta \ln y_{t}^{d}=\underset{(0.022)}{0.018}+\underset{(0.100)}{0.814 \Delta} \ln l_{R, t}^{d}+\underset{(0.002)}{0.0007 t} & \bar{R}^{2}=0.87, D . W .=1.60
\end{array}
$$


where $\Delta \ln y_{t}^{d}$ is the change in log real GNP, $\Delta \ln l_{t}^{d}$ is the change in log total hours worked and $t$ indexes time. The top regression uses Lölhöffel's (1974) annual series; the bottom one has Ritschl's (2002b) data on the right hand side. I use annual data for each regression from 1925 to 1938 . Clearly, the model calibration, namely that $\beta=0.90$, is consistent with the estimated coefficients on $\Delta \ln l_{t}^{d} \cdot{ }^{5}$

\section{$3 \quad$ Unearthing sunspots}

To reiterate, the goal of the paper is to determine whether nonfundamental changes in expectations can explain the fluctuations that occurred in Germany during the interwar period. In the context of the model, in other words, among the infinite number of possible sequences of the expectational errors in (11), I seek the one that best describes the behavior of peoples' extrinsic uncertainty during the 1920s and 1930s period.

Technology shocks are customarily estimated as residuals from a Solow decomposition. In other words, these shocks are not directly observable; measurement takes place within a particular model - a production function. Taking the theoretical model as a starting point, the current paper also tackles deriving sunspots directly from model equations.

Sunspots are unearthed as follows. Let us recall equation (11). In the absence of any other form of uncertainty, the term $\omega_{t+1}$ is a belief shock. By filtering data on per capita consumption, capital and total factor productivity through the model, an empirical sequence of residuals $\left\{\omega_{t}\right\}$ can be computed.

There is no a priori reasoning, however, to expect that the belief shocks are uncorrelated to fundamental disturbances. For example, Pigou (1929) took a somewhat lenient stance on sunspots and has put forth an agnostic interpretation of sunspots as overreactions to fundamental shocks. Here, I define sunspots as the changes to expectations that are not connected to fundamentals. This, then, conforms to a definition of sunspots that is much stricter than Pigou's.

All this is done as follows. The consumption equation residual can be decomposed into a part which is related to TFP shocks and into sunspots. The natural way of orthogonalization is to regress technology shocks on the consumption equation residual. If both shocks are found to be uncorrelated,

\footnotetext{
${ }^{5}$ Ritschl (2002a) finds similar values while using quarterly data. Of course, given the large standard errors of the regressions, the results should be interpreted as indicating that market power and increasing returns are not implausible per se. The large measurement uncertainty is common in empirical studies on scale economies (see Cole and Ohanian, 1999 , for an evaluation).
} 
this would indicate that $\left\{\omega_{t}\right\}$ does not simply capture disturbances on the supply side.

To begin with, German total factor productivity, $z_{t}^{d}$, is tallied by carrying out the Solow decomposition

$$
z_{t}^{d}=\frac{y_{t}^{d}}{\left(u_{t}^{d} k_{t}^{d}\right)^{0.3}\left(l_{t}^{d}\right)^{0.9}}
$$

Here capital utilization is variable and the production function is increasing returns to render the total factor productivity (TFP) estimation compatible with the theoretical model. The instrument for utilization, $u_{t}^{d}$, is taken as HP-deviations of output so as to account for the cyclical intensity that capital is working. The instrument was transformed such that 25 percent of capital was idled at the business cycle trough - consistent with evidence by Bresnahan and Raff (1991). ${ }^{6}$ Since the variables in equation (11) are measured as deviations from the steady state, an estimation of the steady state values is necessary. Accordingly, I linearly detrend all series individually. All data are taken from Ritschl (2002b). The sunspot orthogonalization yields (absolute $t$-value in parentheses, data: 1925:I - 1938:III)

$$
\begin{aligned}
\omega_{t} & =\underset{(0.61)}{-0.125152 \varepsilon_{t}}+\text { sun }_{t} \\
\bar{R}^{2} & =0.008 \quad S E R=0.0306 .
\end{aligned}
$$

Of note is the small explanatory power of the regression as measured by $\bar{R}^{2}$ and the insignificance of the regressor. Technology shocks do not cause the identified belief shocks. Moreover, for serial correlation up to fourthorder, the Breusch-Godfrey test statistics do not reject the null of zero serial correlation (Table 2). Therefore, the sequence of sunspots appears to be in line with the assumption of rational expectations.

Figure 2 shows that pessimism started to engulf the German economy during 1927. In fact I am able to unearth an unfavorable sequence of sunspots from 1927:IV to 1932:II. This sequence roughly coincides with the economic cycle. The business cycle peak occurred in 1928:I and the economy went through its trough in 1932:III. In Figure 3 I display an index of nonfundamental confidence constructed from the sunspot shocks. The index is spawned by chaining the measured innovations from quarter to quarter (i.e. a firstdifference filter). This way, one can clearly observe that confidence reaches a plateau in 1926:IV and its precipitous fall starting during the last quarter

\footnotetext{
${ }^{6}$ Using, say, deviations of per capita output from long term trend as the instrument hardly changes the resulting TFP series - the correlation of the two series is 0.95 . Section 5 will return to the issue.
} 


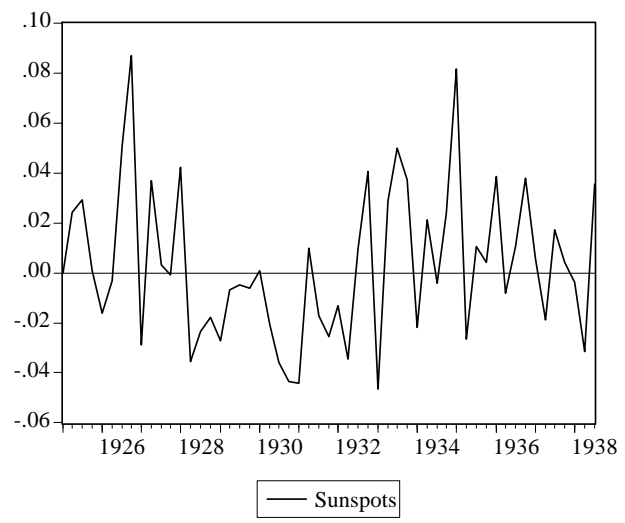

Figure 2: German sunspots as identified from artificial economy

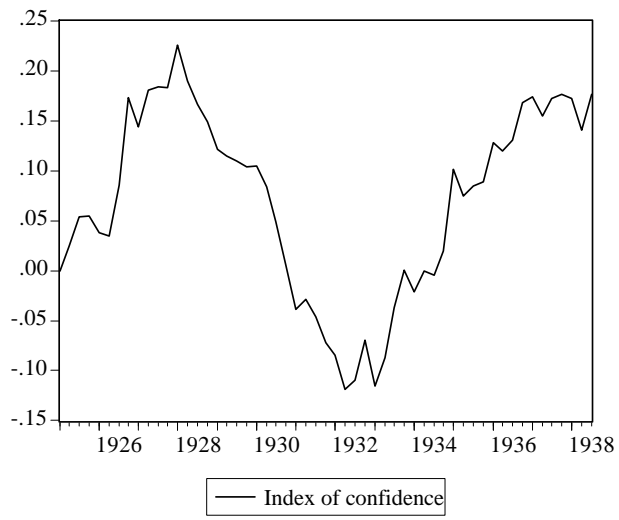

Figure 3: German sunspots index 
of 1927. Confidence does not recover before 1932:II and it continues to rise throughout the 1930s. Only by 1936 does the upsurge comes to a pause. ${ }^{7}$ The findings imply that German expectations changed direction well before the U.S. cycle peaked. This is in line with the hypothesis originally promoted by Temin (1971) and recently picked up again by Ritschl $(1999,2002 \mathrm{a}){ }^{8}$

Next, I address a potential pitfall of the sunspot extracting procedure: Table 3 demonstrates that the measure of nonfundamental confidence is not caused by other fundamental variables. In fact, the causality tests show that considered variables (inflation, government spending, deficit, wage bill, interest rates, and a monetary aggregate) appear not to affect sunspot expectations.

\section{Do sunspots matter?}

Up to this point, I have found indications of pessimistic sunspots that began to surface sometime during 1927. The current Section will trace the economic effects of the estimated worsening of expectations. First I will present results of an empirical investigation to determine how well sunspots predict economic activity. The second part addresses the role of sunspots within a fully specified dynamic general equilibrium. That is, the identified historical sunspots will be fed into the model; data and artificial output series will be confronted.

\subsection{The (forecasting) power of sunspots}

This Subsection determines how well sunspots predict output. It relays the outcome of forecasting regressions for output growth and discusses the findings of a vector autoregression analysis. ${ }^{9}$

I examine the predictive power of sunspots by regressing movements on lagged sunspot innovations on output growth:

$$
\Delta \ln y_{t}^{d}=\alpha+\beta Z_{t}+\sum_{t=i}^{4} \gamma_{i} \operatorname{sun}_{t-i}+\epsilon_{t} .
$$

\footnotetext{
${ }^{7}$ The above sunspot-series is by no means dependent on the way capital utilization is measured in $z_{t}^{d}$. In slight model-inconsistency, I find that the correlation of the above series of sunspots and one that arises when utilization is constant is 0.995 (when both utilization and returns to scale are constant, the correlation is 0.987). I will revisit this issue in Section 5.

${ }^{8}$ In particular Ritschl suggests a worsening of the business climate.

${ }^{9}$ Bram and Ludvigson (1997) conduct a similar exercise to examine the role of confidence on consumption.
} 
Here $\Delta \ln y_{t}^{d}$ is the growth rate of per capita output (data) and $Z_{t}$ is a vector of control variables which comprises of a number of fundamental variables. The control variables included in $Z_{t}$ are the four lags of the growth in the real wage bill and four lags of the first difference of the interest rate (Privatdiskont in Berlin) - the controls are chosen to potentially affecting the path of aggregate demand for other reasons than animal spirits. ${ }^{10}$ Data is quarterly data (1925:I to $1938: \mathrm{IV})$.

The top panel of Table 4 shows estimations of equation (12) without control variables: lagged values of sunspots, taken on their own, explain a substantial portion of output. Specifically, sunspots explain between 11 and 16 percent of the variation in output one quarter hence. ${ }^{11}$ While this finding shows that sunspots by themselves help to predict the future course of output, a more important question is whether sunspots contain information not captured by economic fundamentals. Do sunspots still forecast output to a significant degree once the control variables are included in equation (12)?

The information content of sunspots can be assessed by recording the increment to $\bar{R}^{2}$ from adding sunspots to the regression of economic growth on the control variables. The lower part of Table 4 shows statistical results from running the regression (12) on both the sunspot lags and the control variables; no doubt at econometric risk given that 13 coefficients are being estimated in a sample of 52 observations. In the case of private GNP, the significance of nonfundamental confidence stays put: $\bar{R}^{2}$ rises substantially by 10 percent when sunspots are added to the set of control variables and the coefficients on the four lags of sunspots are estimated to be statistically significant at better than the 1 percent level. As for total GNP, the margin is narrower and the evidence more murky. Sunspots contribute about 8 percent to the $\bar{R}^{2}$ and, more importantly, the four lags are only jointly significant at only the 6 percent level.

For an alternative way to gauge whether sunspots have had much of a role in accounting for movements in output, Table 5 reports variance decompositions for various time horizons based on the 1925 to 1938 estimation period. In a sense, variance decompositions of this sort are a harder test than simply comparing the output amplitudes of data and of the sunspot driven model as is normally done in the real business cycle literature (RBC). ${ }^{12}$ Underlying the

\footnotetext{
${ }^{10}$ Of course, the choice of which controls to include is inherently somewhat arbitrary. Interest rate and wage income can be thought of capturing effects of monetary policy and credit-rationing.

${ }^{11}$ Private output is defined as the sum of non-government consumption and investment spending. For our purposes, it appears to be the relevant variable. At the beginning of the sample (1925) private output was 87 percent of total output.

${ }^{12}$ In fact, when the sequence of sunspots is fed into the model, the model variance
} 

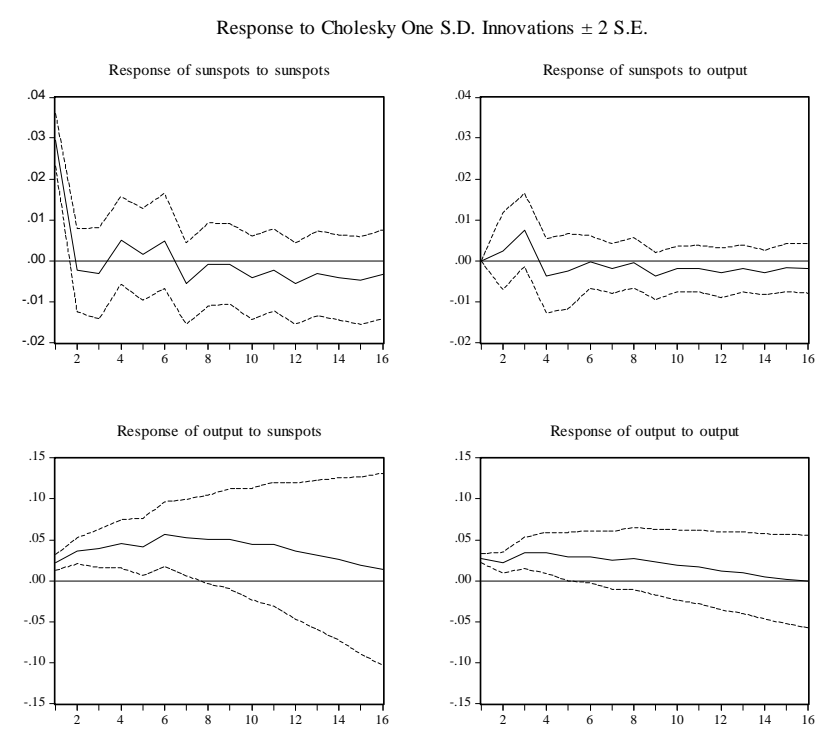

Figure 4: Impulse responses. VAR as in Table 5.

analysis is a bivariate, unrestricted vector autoregression (VAR) containing sunspots and output. Sunspots are ordered first in the VAR. This is consistent with the assumption that sunspots influence output contemporaneously, but output influences expectations only with a one period lag. The VARs suggest that sunspots account for between 25 percent to 75 percent of the output forecast variance at a three year horizon.

Figure 4 summarizes the dynamic relationship between sunspots and output. The chart shows the responses of log private output to an innovation in confidence. The lines above and below the impulse response are the probability bands which are generated by taking 1000 Monte Carlo draws from the posterior distribution of the VAR coefficients. The Figures illustrate that sunspot shocks have a very persistent effect on output. The strongest response is about one-and-a-half years after the impact. ${ }^{13}$

Overall, I interpret these results as an indication of sunspots' pertinent role during the Great Depression. Granted the analysis up to now did not consider the model and - at this point of the discussion - it is not clear

exceeds data's by factor three. The reasoning for this is that in the presence of variable capital utilization, consumption becomes extremely smooth. There is a solution to this puzzle by departing from logarithmic utility (see Weder, 2002). Since I am only engaged in regressions in the following Sections, the scaling (as in Figure 5) is not important.

${ }^{13}$ The respective charts for total output are very similar, however, the (initial) output response is cut by 30 percent and the pattern is somewhat less persistent. 
whether theory would in fact produce a sequence of artificial economic activity that resembles that of the actual economy. This is will be shown in the following Sections.

\subsection{Injecting sunspots - a visual clue}

The following Subsections will provide clues of how sunspot theory tracks the German interwar cycle. To that avail, an artificial output series is derived by feeding the empirical sunspot series back into the model (11). The procedure encompasses tautology and unlike Chari, Kehoe and McGrattan's (2002) accounting scheme, there is nothing to expect that every facet of the business cycle can be explained by the sunspots shocks. First of all, sunspots have been derived from a subset of equations that constitute the general equilibrium of the economy and therefore the procedure is not an accounting exercise. Second, the very sequence of estimated shocks is dependent on the specific theoretical model. If the model is a poor description of the German economy, the shocks should be significant in the sense of adjusting the model's prediction such to pick up alternative sources of fluctuations. This, however, was not the case: the causality tests suggested that nothing out of the list of fundamental forces drives the sunspots. ${ }^{14}$ On the other hand, if the model is correct and able to pick up the real sunspots, but sunspots are not an important source of the German cycle, then it should be expected that the model and German output data differ substantially. The following Subsections attempt to monitor any such differences.

Before conducting quantitative tests, Figure 5 graphically presents the behavior of artificial output. The model economy does extremely well in capturing the general pattern of output. That is, the model correctly reaches a plateau in 1927, it predicts the upper turning point, the slide into the Depression as well as the beginning of the recovery more than four years later.

\subsection{Sunspot theory in action}

Figure 5's graphical characterization remains uninformative unless a quantitative test of the sunspot theory of the Great Depression is provided. This will be done next.

A natural starting point is to regress model output, $y_{t}^{m}$, on linearly de-

\footnotetext{
${ }^{14}$ Moreover, if, say, technology shocks were the exclusive impulse behind the German cycle, the model would record these shocks but not measure any $\omega_{t}$-sequence.
} 


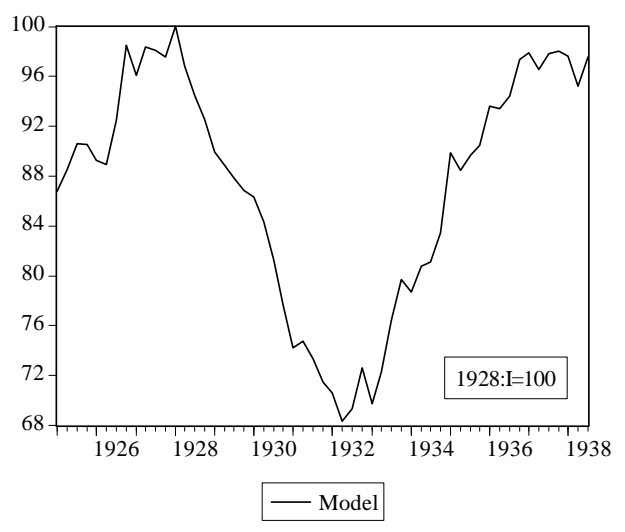

Figure 5: Artificial output. Scaled to match 75 percent of data volatility.

trended total output ( $t$-values in parentheses):

$$
\begin{aligned}
\ln y_{t}^{t, d} & =\underset{(4.27)}{0.824}+\underset{(18.86)}{0.825 \ln y_{t}^{\mathrm{m}}} \\
\bar{R}^{2} & =0.868 \quad S E R=0.0518 \\
\ln y_{t}^{t, d} & =\underset{(4.41)}{0.715}+\underset{(23.10)}{0.850 \ln } y_{t-1}^{\mathrm{m}} \\
\bar{R}^{2} & =0.909 \quad S E R=0.0432
\end{aligned}
$$

and on private output

$$
\begin{aligned}
\ln y_{t}^{p, d} & =\underset{(2.19)}{0.538}+\underset{(15.80)}{0.880} \ln y_{t}^{\mathrm{m}} \\
\bar{R}^{2} & =0.822 \quad S E R=0.0660 \\
\ln y_{t}^{p, d} & =\underset{(1.76)}{0.349}+\underset{(20.59)}{0.923 \ln } y_{t-1}^{\mathrm{m}} \\
\bar{R}^{2} & =0.889 \quad S E R=0.0526 .
\end{aligned}
$$

At first glance, these regressions evoke that the sunspot model mimics fairly closely the actual behavior of output: the coefficients are highly significant and a substantial fraction of the sample variance is explained. Moreover, whenever the artificial economy appears in lagged form, the regressions improve which indicates that model output leads the German cycle. Nevertheless, the above regressions cannot be seen as a logical affirmation in favor 
of or against a sunspot-based interpretation of the German Depression: the ability to mimic the economy's cyclical pattern is a necessary but not a sufficient condition that any theory should be able pass. Stronger evidence would be to show that sunspots provide added apprehension over rival modelling structures (see also Salyer and Sheffrin, 1998, which I follow here).

Time series econometrics allows data to be distinguished in atheoretical ways. For example, modelling aggregate output as a low-order autoregressive or moving-average process generates a reasonable fit. If the sunspot approach to business cycles conveys anything unique about the German economy it must provide some advantage relative to atheoretical time series models. I implement this investigation by estimating equations of the following form

$$
\ln y_{t}^{d}=\alpha+\sum_{i=1}^{n} \beta_{i} \ln y_{t-i}^{d}+\gamma \ln y_{t}^{\mathrm{m}}+\epsilon_{t} .
$$

The idea behind conducting these tests is that by adding output from the sunspot model to the regression, one obtains a measure of to what extent sunspots provide additional informational content.

Let us begin with the autoregressive model. A lag length of $n=3$ (4) was determined to remove fourth-order serial correlation for private (total) GNP. The time series model's predictive power is large - it explains over 93 percent of the variation in output one quarter hence (Lines 1 and 3 in Table 6 ). The Table also shows that the sunspot model contains incremental explanatory power on private and total output (Lines 2 and 4). The standard errors of the regressions fall by 15 (11) percent and the probability that the explanatory power is produced by pure chance is essentially nil. ${ }^{15}$

A natural alternative is to check the forecasting ability of the sunspot model, since after all, sunspots represent forward-looking expectations. This alternative hypothesis is represented in the following equation

$$
\ln y_{t}^{d}=\alpha+\sum_{i=1}^{n} \beta_{i} \ln y_{t-i}^{d}+\sum_{i=1}^{m} \gamma_{i} \ln y_{t-i}^{\mathrm{m}}+\epsilon_{t} .
$$

Table 7 reports. In the first row, the dependent variable is data output (private) alone. The next line adds one period lagged model output which is followed by the case $m=4$. The sunspot model, again, has explanatory power. For example, there is a 16 to 18 percent reduction of the standard errors in the regression relative to Line 1 . The results for total output are somewhat worse. The one-period lagged artificial output is endowed with

\footnotetext{
${ }^{15}$ It can furthermore be shown that adding the sunspots model to the regression does not create serial correlations.
} 
incremental predictive power, however, the distributed lag of artificial output is not jointly significant at reasonable probability values (Lines 5 and 6 of Table 7). However, given the dramatic increase of government expenditures on GNP - from 13 percent in 1925 to 32 percent in 1938 -, the lower correlation is not dramatically surprising.

\section{Robustness and extensions}

This Section discusses the robustness of the previous results. The Section first checks for the sensitivity of linearly detrending variables before filtering out sunspots. It then looks at different measures of TFP and the explanatory power of technology shocks. This is followed by considering a model version in which technology is constant and I show that variable factor utilization and increasing returns to scale provide an endogenous mechanism for explaining movements in the naive Solow residual. I then check for robustness by employing an alternative labor series and by considering a different representation of the model from which sunspots are extracted. Finally, I will show robustness of my results by applying alternative methods of unearthing sunspots and then compare the results.

\subsection{Detrending}

Since the variables in equation (11) were measured as deviations from the steady state, an estimation of the steady state values was necessary. In Section 3 and 4, I used linearly detrended series. Here, I apply a HodrickPrescott filter instead. This yields

$$
\begin{aligned}
\omega_{t} & =\underset{(0.65)}{-0.11967 \varepsilon_{t}+\operatorname{sun}_{t}} \\
\bar{R}^{2} & =0.007 \quad S E R=0.0274 .
\end{aligned}
$$

The correlation of the sunspot sequence here and that from Section 3 is 0.98. Table 8 shows the minor effects of an alternative detrending on model predictions. The artificial economy stays put.

\subsection{Noise in TFP}

One objection to the extracting procedure could be that measured TFP may be a noisy signal of true supply shocks (largely arising from the construction of historical quarterly data series). To combat this, I add four lagged TFP shocks as right hand side variables in the orthogonalization of the belief 


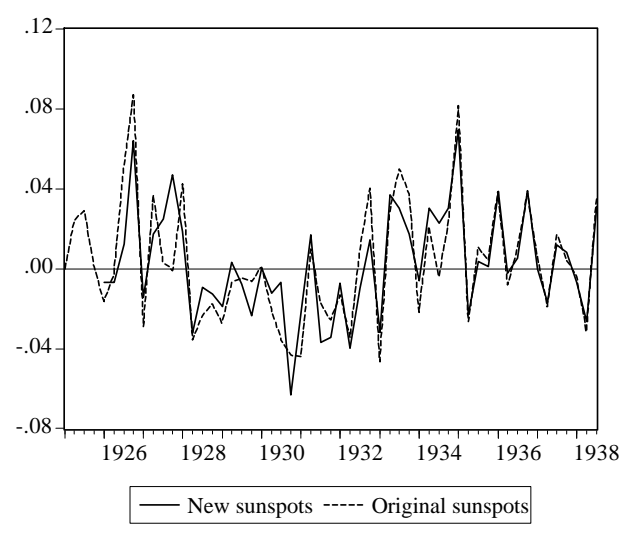

Figure 6: Sunspots. Old and new.

shock. This raises $\bar{R}^{2}$ to 0.191 but the new shock series looks very much like the first sunspot sequence: the contemporaneous correlation is 0.86 (Figure $6) .{ }^{16}$ The predictive power of sunspots remains. The shocks taken on their own explain between 16 to 31 percent of the one-quarter-ahead variation in output growth (Table 9). ${ }^{17}$ Sunspots also contain significant information about future changes of private output aside from the information contained in the control variables. In the case of total output, sunspots add only 2 percent to the $\bar{R}^{2}$ of the reduced-form equation and the four lags are not jointly significant at any of the usual levels. Table 10 reports explanatory power of the artificial economy at the 6 percent level or better. I conclude that even though the results for total output are somewhat discouraging, the results for private spending remain quite strong.

\subsection{The role of technology shocks}

At the stage of sunspot estimation, technology was assumed to be stochastic. It would therefore be logical to move to a model that contains TFP shocks. Let us begin by shutting down the sunspot channel and shock the model (11) only by the identified shocks to efficiency, $z_{t}$.

Ever since Burnside and Eichenbaum (1996), it is known that variable capital utilization impinges on measured TFP. Table 11 reports. A real business cycle version of the model contains valuable information. However, the

\footnotetext{
${ }^{16}$ Of course, TFP itself may be a noisy measure of true supply shocks (see Hall, 1990) and the more pronounced effect on $\omega$ may be artifact of the persistent cycle.

${ }^{17}$ Actually, when compared to Table 4, the regressions are not worse than those in which "less TFP noise" is taken out.
} 
informational content is abruptly lost for lagged realizations which indicates that the supply driven economy is lagging. ${ }^{18}$ It should, of course, be emphasized that the result is dependent on the current model and, thus, the results are to some extent unfair to the RBC approach. Taken together, however, the Subsection finds that sunspots models are certainly not inferior to RBC and furthermore, it points to the possibility that factors other than the broadly defined shock to efficiency may be chiefly responsible for the interwar cycle.

\subsection{No role for technology shocks?}

This said, it appears that shutting down the channel of intertemporal substitutions of TFP shocks may be an adequate strategy to divulge the riddle of the Great Depression. This now creates a puzzle of its own: how can this be feasible after the variations in TFP are a fact (see for example Fisher and Hornstein, 2002)? I conduct the following experiment. TFP can be computed as the residual from a naive Solow-residual accounting in which all TFP-movements are attributed to technology

$$
z_{t}^{c r s}=\frac{y_{t}}{k_{t}^{0.25} l_{t}^{0.75}}
$$

In (13) I now ignore both variable capital utilization and increasing returns as do Fisher and Hornstein (2002). I then ask, is the artificial sunspots economy able to endogenously replicate the $z_{t}^{\text {crs }}$-pattern? Let us assume that technology is deterministic. Thus, the economy is best described by

$$
\left(\begin{array}{c}
\widehat{c}_{t+1} \\
\widehat{k}_{t+1}
\end{array}\right)=\mathbf{F}\left(\begin{array}{c}
\widehat{c}_{t} \\
\widehat{k}_{t}
\end{array}\right)+\mathbf{G}\left(\begin{array}{c}
\omega_{t+1} \\
0
\end{array}\right)
$$

and sunspots are elicited accordingly. The matrix $\mathbf{F}$ is $2 \times 2$. The economic structure parallels the approach taken in Farmer and Guo (1994). Figure 7 plots the original shock sequence and the new series. Quite remarkably, the sequences are just about identical - their correlation is 0.988 - which suggests that consumption shocks, $\omega_{t+1}$, are essentially unconnected to contemporaneous innovations to TFP. Figure 8 plots the computed naive model TFP vis-a-vis data- $z_{t}^{c r s}$. Because of the presence of increasing returns and of variable capacity utilization in the model, sunspot shocks lead to a procyclical series of naive TFP. The correlation of artificial and data TFP is quite large; even when Lölhöffel's data is used it is 0.94 .

\footnotetext{
${ }^{18}$ For total output, the real business cycle model always has insignificant, negative coefficients.
} 


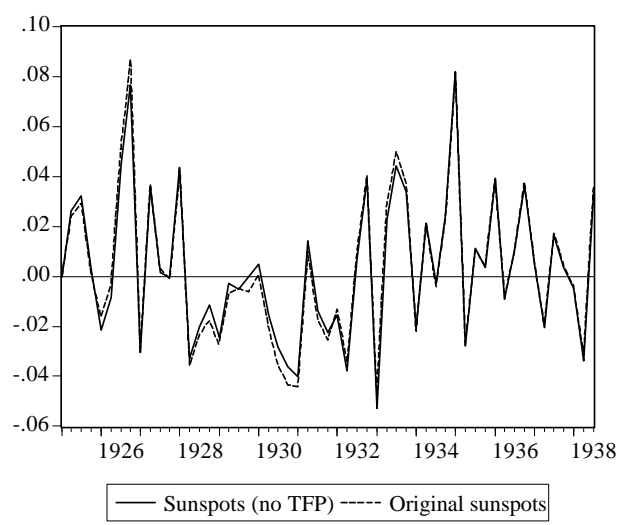

Figure 7: Sunspots when TFP is not in model

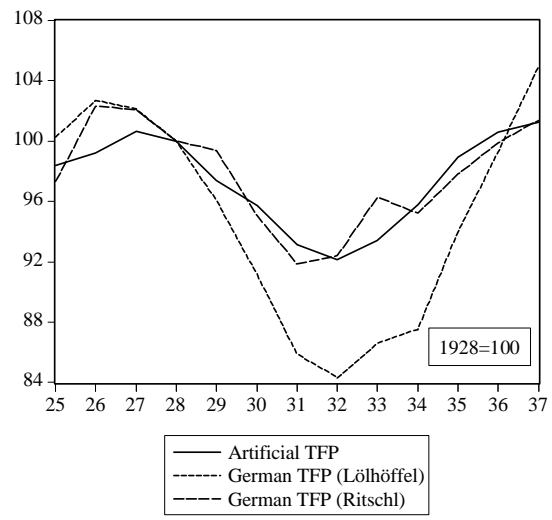

Figure 8: Artificial TFP. Data TFP constructed by using Lölhöffel's and Ritschl's employment series. German TFP detrended by sample trend to make both series comparable to model (trend for the series is 2 percent and 1.76 percent resp.). 


\subsection{Robustness with respect to employment data}

Given the discussion on TFP and Fisher and Hornstein's (2002) use of Lölhöffel's employment series, it should be checked if my results can be replicated when TFP is computed based on Lölhöffel's employment data. Lölhöffel's and Ritschl's series differ in the way the employment in the government sector is accounted for. Ritschl's data is a better representation for non-government employment than Lölhöffel's and it is more volatile. As a consequence, TFP falls less during the Depression era (see Figure 8).

I use a cubic spline method to transform Lölhöffel's annual data into quarterly frequency. Once again, I find that belief shocks and technology shocks are not correlated as the orthogonalization evinces ( $t$-values in parentheses):

$$
\begin{aligned}
\omega_{t} & =\underset{(1.34)}{0.23282 \varepsilon_{t}+\text { sun }_{t}} \\
\bar{R}^{2} & =0.029 \quad S E R=0.0322 .
\end{aligned}
$$

The coefficient of technology shocks now has the expected positive sign, however, it is still not significant. Table 12 shows the significant predictive power of sunspots. I then add output from the sunspot model to the regression

$$
\ln y_{t}^{d}=\alpha+\sum_{i=1}^{n} \beta_{i} \ln y_{t-i}^{d}+\gamma \ln y_{t}^{\mathrm{m}}+\epsilon_{t}
$$

to obtain a measure of to what extent sunspots provide informational content. The specific model is driven by expectational shocks only. Table 13 reports; the analysis is analog to Table 5 to which it should be compared. Artificial output again possesses significant explanatory power. I conclude that my results are robust with respect to the specific employment series.

\subsection{A different model reduction}

Next, I will demonstrate the non-importance of reducing the dynamic system to (11). In the case of the German Depression, Temin's (1971) story concerns an early fall in investment. Thus, the natural question arises if there is any gain from identifying the sunspots with a residual from the investment equation (i.e. animal spirits) rather than from the consumption equation in (11) ? $^{19}$ To address this, I will consider a rearranged reduced-form version of the model that includes investment instead of consumption:

$$
\left(\begin{array}{c}
\widehat{x}_{t+1} \\
\widehat{k}_{t+1}
\end{array}\right)=\mathbf{S}\left(\begin{array}{c}
\widehat{x}_{t} \\
\widehat{k}_{t}
\end{array}\right)+\mathbf{B}\left(\begin{array}{c}
\widetilde{\omega}_{t+1} \\
0
\end{array}\right) .
$$

\footnotetext{
${ }^{19}$ I would like to thank Stephen Broadberry for suggesting this to me.
} 


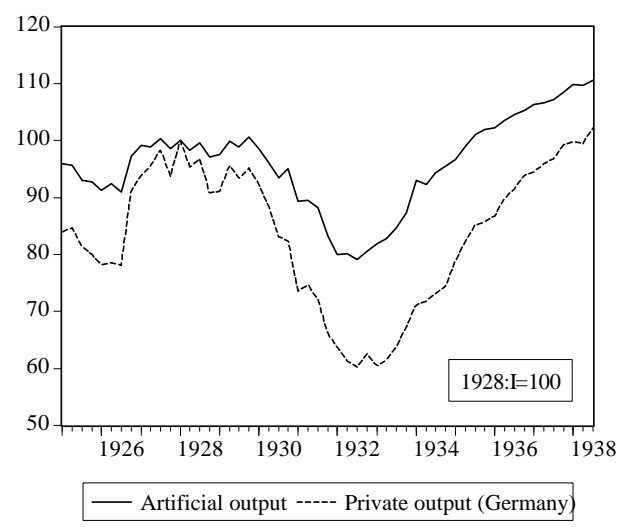

Figure 9: Artificial output.

As before, $\mathbf{S}$ denotes the $2 \times 2$ Jacobian and $\widetilde{\omega}_{t+1} \equiv E_{t} \widehat{x}_{t+1}-\widehat{x}_{t+1}$. I use this equation to again extract sunspots. Figure 9 shows that the sunspot-driven economy tracks real data quite well. The artificial economy peaks in 1928:I, turns around in 1932:III and predicts a long boom after that. Moreover, the sunspot driven economy accounts for 45 percent of German output standard deviation (see also footnote 10 on that issue). Table 14 shows that explanatory model power endures. The economic reason for the equivalence of both modelling structures is that consumption and investment share an important characteristic: they are both forward-looking, thus, changes in expectations are captured in the behavior of both variables.

\subsection{The Salyer and Sheffrin approach to sunspots}

Salyer and Sheffrin (1998) compute sunspots with an alternative modelling structure. In particular, they employ financial markets data in an extended Farmer and Guo (1994) indeterminacy model. For further robustness of my results, I shall repeat their procedure for interwar Germany. Data on interest rates is inflation-deflated (Privatdiskont, source of data Ritschl, 2002b). Table 15 shows the forecasting power of the sunspots. The influence of sunspots is significant. When sunspots are fitted back into model, I find that the artificial business cycle peaks in 1926:IV - which is a bit earlier than what my original sunspots series predicted - and the beginning of the economic rundown comes about three quarters later (Table 16 presents regressions results). This coincides with the sunspot series which were previously derived. 


\subsection{The Harrison and Weder approach to sunspots}

Harrison and Weder (2001) promote an alternative procedure to filter out expectations from data. They do not use a specific theoretical model to estimate sunspots but rather quantify investor's sentiment by instrumenting it by interest rate spreads. Using their VAR-based approach, one must not impose a priori assumptions on the correct model structure at the stage of sunspot computations (see Beyer and Farmer, 2003, for a recent discussion of identification problems of rational expectations models). Harrison and Weder claim that spreads between high and medium-graded corporate bonds embody important information on agents' forecasts. For example, a widening of the spread in advance of business cycle downturns reflects anticipation on the part of investors that a downturn is likely. Default by (lower-graded) borrowers has become relatively more plausible. ${ }^{20}$ It is thus routine to ask if the Harrison-and-Weder-procedure yields similar results; if it does it would provide auxiliary evidence to the findings here. I apply the Harrison-Weder-procedure while taking bonds with the lowest perceived default risk (H.A.B. Pfandbriefe) as the natural benchmark and industrial corporate bonds (Industrieobligationen) as the measure of risk. The spread between the bonds' returns opens during the second part of $1927 .{ }^{21}$ I extract non-fundamental uncertainty by estimating a bivariate, two-lagged VAR containing the spread and output growth. The part of the spread that is not explained (and therefore orthogonal to GNP) is interpreted as a rough measure of sunspots. Figure 10 plots the spread residuals after adjusting for fundamental inputs vis-a-vis the model-based shocks as computed above. Their correlation is 0.47 .

\section{Concluding comments}

There are many speculations when it comes to solving the riddle of the Great Depression in Germany. Existing theories often stress fundamental imbalances and distortions, like TFP deteriorations, inept fiscal policy, reparations,

\footnotetext{
${ }^{20}$ Bernanke (1990) and Friedman and Kuttner (1993) also use the Baa-Aaa-quality spread as an instrument for perceived default risk. Ritschl (1999) interprets the detoriation of the term-structure as investors' prediction of the slump.

${ }^{21}$ Data taken from Statistisches Jahrbuch für das Deutsche Reich (years 1926-1933). Bond data sample limited to create consistent series: months 1931:8 to 1932:4 not avaiable; later periods missing. I estimated the VAR including and excluding (i.e. 1925 to 1931) the missing period. The general results are robust with respect to the estimation period, lag lengths and ordering of variables. Harrison and Weder's U.S. data covers well over 300 observations which allows for the correction of further fundamental variables such as money, interest rates, default rates et cetera.
} 


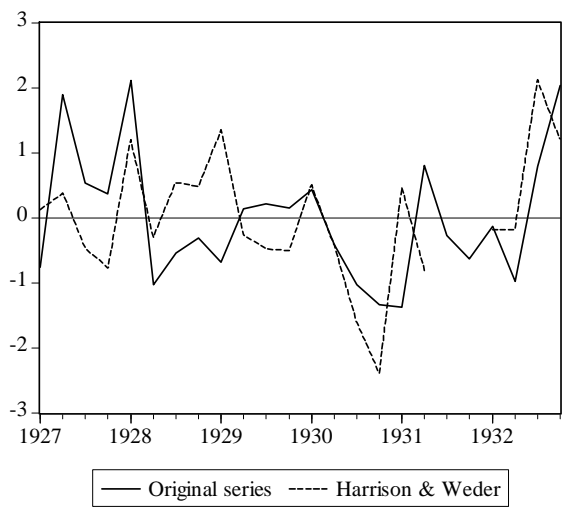

Figure 10: VAR sunspots versus original sunspots. Normalized data.

taxes et cetera and all have put forth plausible but certainly not fully convincing accounts. The present paper challenges the view that matters were purely fundamental. I find that nonfundamental factors played a prominent role. In particular, my analysis has tracked down historical sunspots that had a ripple effect on the German economy. The paper shows that sunspots contain important information on economic activity and it points to a tangible fraction of output volatility that is directly attributable to nonfundamental expectations. Most notable is that the detrimental shocks began to hit the economy well before other disturbances (such as the rise in real interest rates, Gold exports or financial panics) entered the picture. Sunspots therefore offer a reason for the early beginning of the Depression in Germany. In a sense, the paper provides the theoretical backbone to Temin's (1971) interpretation of the German Depression. Temin stresses a fall in domestic investment demand, however, he leaves unexplained what caused the plunge. The current paper makes a case for a dramatic swing towards pessimistic expectations that developed during 1927 which depressed aggregate demand and persisted until the later half of 1932. 


\section{References}

[1] Basu, Susanto, and John G. Fernald (1997): "Returns to Scale in U.S. Production: Estimates and Implications," Journal of Political Economy 105, 249-283.

[2] Benhabib, Jess and Roger E. A. Farmer (1999): "Indeterminacy and Sunspots in Macroeconomics", in John B. Taylor and Michael Woodford (editors) Handbook of Macroeconomics, Elsevier, North-Holland, (Volume 1A) 387-448.

[3] Bernanke, Ben S. (1990): "On the Predictive Power of Interest Rates and Interest Spreads", New England Economic Review (November/December), 51-68.

[4] Bernanke, Ben S. and Martin L. Parkinson (1991): "Procyclical Labor Productivity and Competing Theories of the Business Cycle: Some Evidence from Interwar U.S. Manufacturing Industries", Journal of Political Economy 99, 869-902.

[5] Beyer, Andreas and Roger E. A. Farmer (2003): "On the Indeterminacy of Determinacy and Indeterminacy", ECB \& UCLA, mimeographed.

[6] Burnside, Craig and Martin S. Eichenbaum (1996): "Factor Hoarding and the Propagation of Business Cycle Shocks", American Economic Review 86, 1154-1174.

[7] Bloch, Kurt (1932): "On German Cartels", The Journal of Business of the University of Chicago 5, 213-222.

[8] Bram, Jason and Sydney Ludvigson (1997): "Does Consumer Confidence Forecast Household Expenditure? A Sentiment Index Horse Race", Federal Reserve Bank of New York Research Paper \#9708.

[9] Bresnahan, Timothy and Daniel Raff (1991): "Intra-industry Heterogeneity and the Great Depression: The American Motor Vehicles Industry, 1929-1935", Journal of Economic History 51, 317-331.

[10] Chari, V. V., Patrick J. Kehoe and Ellen R. McGrattan (2002): "Accounting for the Great Depression", American Economic Review (Papers and Proceedings) 92, 22-27. 
[11] Cole, Harold L. and Lee E. Ohanian (1999): "Aggregate Returns to Scale: Why Measurement is Imprecise", Federal Reserve Bank of Minneapolis Quarterly Review 23, 19-28.

[12] Farmer, Roger E. A. and Jang-Ting Guo (1994): "Real Business Cycles and the Animal Spirits Hypothesis", Journal of Economic Theory 63, 42-73.

[13] Fisher, Jonas D. M. and Andreas Hornstein (2002): "The Role of Real Wages, Productivity, and Fiscal Policy in Germany's Great Depression", Review of Economic Dynamics, 5, 100-127.

[14] Friedman, Benjamin M. and Kenneth N. Kuttner (1993): "Why Does the Paper-Bill Spread Predict Real Economic Activity", in James H. Stock and Mark W. Watson (editors) Business Cycles, Indicators and Forecasting, NBER Studies in Business Cycles Volume 28, Chicago University Press, Chicago, 213-249.

[15] Greenwood, Jeremy, Zvi Hercowitz and Gregory Huffman (1988): "Investment, Capacity Utilization, and the Real Business Cycle", American Economic Review 78, 402-417.

[16] Harrison, Sharon G. and Mark Weder (2001): "Did Sunspot Forces Cause the Great Depression?", CEPR Discussion Paper \#3267.

[17] Hall, Robert E. (1990): "Invariance Properties of Solow's Productivity Residual", in Peter Diamond (editor) Growth Productivity, Unemployment, MIT Press, Cambridge, 71-112.

[18] Kellenbenz, Hermann (1981): Deutsche Wirtschaftsgeschichte, BeckVerlag, München.

[19] Kindleberger, Charles P. (1986): The World in Depression: 1929-1939 (2nd edition), University of California Press, Berkeley.

[20] Lölhöffel, M. von (1974): "Zeitreihen für den Arbeitsmarkt-Lohnsatz, Beschäftigungsfälle, Arbeitskosten und Arbeitsstunden", Ifo Studien 20, $33-150$.

[21] Lucas, Robert E. Jr. (1977): "Understanding Business Cycles", reprinted in Robert E. Lucas Jr. (1981): Studies in Business Cycle Theory, Basil Blackwell, Oxford. 
[22] Pigou, Arthur C. (1929): Industrial Fluctuations, MacMillan, London.

[23] Ritschl, Albrecht (1999): "Peter Temin and the Onset of the Great Depression in Germany: A Reappraisal", University of Zürich, mimeographed.

[24] Ritschl, Albrecht (2002a): "Dancing on a Volcano: The Economic Recovery and Collapse of the Weimar Republic, 1924-1933", in: T. Balderston (editor), World Economy and National Economies in the Interwar Slump, Macmillan, London.

[25] Ritschl, Albrecht (2002b): Deutschlands Krise und Konjunktur 19241934 - Binnenkonjunktur, Auslandsverschuldung und Reparationsproblem zwischen Dawes-Plan und Transfersperre, Akademie Verlag, Berlin.

[26] Salyer, Kevin D. and Steven M. Sheffrin (1998): "Spotting Sunspots: Some Evidence in Support of Models with Self-Fulfilling Prophecies", Journal of Monetary Economics 42, 511-523.

[27] Sweezy, Maxine Y. (1940): "German Corporate Profits: 1926-1938", Quarterly Journal of Economics 54, 384-398.

[28] Temin, Peter (1971): "The Beginning of the Great Depression in Germany", Economic History Review 24, 240-248.

[29] Weder, Mark (2003): "Some Observations on the Great Depression in Germany", CEPR Discussion Paper \#3716.

[30] Weder, Mark (2002): "A Note on Consumption Volatilities in Indeterminacy Models", Humboldt University Berlin, mimeographed.

[31] Wen, Yi (1998): "Capacity Utilization under Increasing Returns to Scale", Journal of Economic Theory 81, 7-36.

\section{The linearized model and the tables}

Let us denote $\widehat{y}_{t} \equiv\left(y_{t}-y\right) / y$ et cetera, then the linear model is given by

$$
\begin{gathered}
\widehat{y}_{t}=\alpha \widehat{u}_{t}+\alpha \widehat{k}_{t}+\beta \widehat{l}_{t} \\
\widehat{l}_{t}=\widehat{y}_{t}-\widehat{c}_{t}
\end{gathered}
$$




$$
\begin{gathered}
\widehat{\delta}_{t}=\widehat{y}_{t}-\widehat{k}_{t} \\
\widehat{\delta}_{t}=\theta \widehat{u}_{t} \\
\frac{c}{y} \widehat{c}_{t}+\frac{x}{y} \widehat{x}_{t}=\widehat{y}_{t} \\
-\widehat{c}_{t}=-E_{t} \widehat{c}_{t+1}+\alpha v \rho \frac{y}{k}\left(E_{t} \widehat{y}_{t+1}-\widehat{k}_{t+1}\right)-\rho \delta E_{t} \widehat{\delta}_{t+1} \\
\widehat{k}_{t+1}=(1-\delta) \widehat{k}_{t}-\delta \widehat{\delta}_{t}+\frac{x}{k} \widehat{x}_{t}
\end{gathered}
$$

and

$$
\widehat{z}_{t+1}=\zeta \widehat{z}_{t}+\varepsilon_{t+1} .
$$

Table 1: Quarterly model calibration

\begin{tabular}{|c|c|c|c|c|c|}
\hline$\alpha v$ & $\beta v$ & $\rho$ & $\delta$ & $v$ & $\zeta$ \\
\hline 0.25 & 0.75 & $1.03^{-1 / 4}$ & 0.0075 & 0.83 & 0.95 \\
\hline
\end{tabular}

\begin{tabular}{|c|c|}
\hline \multicolumn{2}{|c|}{ Table 2: Serial correlation } \\
\hline Lags & Probability \\
\hline 1 & 0.60 \\
\hline 2 & 0.86 \\
\hline 3 & 0.55 \\
\hline 4 & 0.62 \\
\hline
\end{tabular}

Table 2 - Serial correlation LM test: Breusch-Godfrey tests (various orders) for autocorrelated disturbances (probability values). 


\begin{tabular}{|l|l|l|l|}
\hline \multicolumn{4}{|l|}{ Table 3: Granger causality (probability) } \\
\hline Variable & Lags & \multicolumn{3}{l|}{} \\
\cline { 2 - 4 } & 2 & 4 & 6 \\
\hline Deficit (real) & $0.52 / 0.59$ & $0.13 / 0.09$ & $0.32 / 0.77$ \\
\hline Deficit/Y & $0.51 / 0.59$ & $0.07 / 0.74$ & $0.23 / 0.80$ \\
\hline $\mathrm{G}$ & $0.82 / 0.30$ & $0.99 / 0.66$ & $0.87 / 0.66$ \\
\hline $\mathrm{G} / \mathrm{Y}$ & $0.81 / 0.76$ & $0.96 / 0.99$ & $0.76 / 0.90$ \\
\hline $\mathrm{M} / \mathrm{P}$ & $0.92 / 0.25$ & $0.99 / 0.31$ & $0.91 / 0.33$ \\
\hline Wage bill & $0.64 / 0.16$ & $0.58 / 0.12$ & $0.58 / 0.08$ \\
\hline Interest rate & $0.89 / 0.75$ & $0.90 / 0.71$ & $0.89 / 0.39$ \\
\hline Inflation & $0.33 / 0.10$ & $0.09 / 0.00$ & $0.14 / 0.01$ \\
\hline
\end{tabular}

Table 3 - The first (second) entry corresponds to the probability value of the null that "the variable (sunspots) does not Granger cause sunspots (the variable)". Deficit $=$ change of real deficit, Deficit $/ \mathrm{Y}=$ change of real deficit as fraction of output, $\mathrm{G}=$ growth rate of real government expenditure, $\mathrm{G} / \mathrm{Y}=$ change of government share, $\mathrm{M} / \mathrm{P}=$ real money (base) growth, Wage bill = growth rate of real wage bill, Interest rate $=$ Privatdiskont in Berlin, Inflation $=$ growth rate of CPI.

Table 4: Predictive power of sunspots

\begin{tabular}{|l|l|l|}
\hline Dependent & $\bar{R}^{2}$ or $\Delta \bar{R}^{2}$ & $\begin{array}{c}\text { Significance } \\
(p \text {-value })\end{array}$ \\
\hline GNP $^{\text {rivate }}$ & 0.161 & 0.010 \\
\hline $\mathrm{GNP}^{\text {total }}$ & 0.117 & 0.032 \\
\hline \hline $\mathrm{GNP}^{\text {rivate }}$ & 0.107 & 0.006 \\
\hline $\mathrm{GNP}^{\text {total }}$ & 0.079 & 0.051 \\
\hline
\end{tabular}

Table 4 - The upper part reports $\bar{R}^{2}$ and the lower one changes in $\bar{R}^{2}$ after sunspots are added to regression. The third column displays probability values of the null that the sunspot variable is zero (log likelihood ratio).

\begin{tabular}{|l|l|l|l|l|}
\hline \multicolumn{5}{|c|}{ Table 5: Sunspot shocks: variance decomposition } \\
\hline Period & $\Delta \ln y^{T}$ & $\ln y^{T}$ & $\Delta \ln y^{P}$ & $\ln y^{P}$ \\
\hline 0 & 23.3 & 24.1 & 41.4 & 40.0 \\
\hline 4 & 26.6 & 24.4 & 49.2 & 61.8 \\
\hline 8 & 27.0 & 28.2 & 49.8 & 71.9 \\
\hline 12 & 27.1 & 30.4 & 49.8 & 75.3 \\
\hline
\end{tabular}


Table 5 - Cholesky ordering: sunspots, output. VAR containing total output growth $\left(\Delta \ln y^{T}\right)$ and private output growth $\left(\Delta \ln y^{P}\right)$ has lag length 3 . VAR containing total output growth $\left(\Delta \ln y^{T}\right)$ and private output growth $\left(\Delta \ln y^{P}\right)$ has lag length 5 (detrended); lags determined by Akaike info criteria and Schwarz criteria.

\begin{tabular}{|c|c|c|c|c|c|c|}
\hline \multicolumn{7}{|c|}{ Table 6: Regression results } \\
\hline Line & Variable & $\begin{array}{c}\text { Coefficient } \\
(t \text {-value })\end{array}$ & $\bar{R}^{2}$ & S.E.R. & $\begin{array}{c}\text { F-statistic } \\
(\text { variable })\end{array}$ & $\begin{array}{c}\text { Log likelihood } \\
\text { ratio }\end{array}$ \\
\hline 1 & - & - & 0.938 & 0.0399 & - & - \\
\hline 2 & $\mathrm{y}^{m}$ & $\begin{array}{c}0.342 \\
(6.56)\end{array}$ & 0.967 & 0.0291 & 0.000 & 0.000 \\
\hline 3 & - & - & 0.955 & 0.0311 & - & - \\
\hline 4 & $\mathrm{y}^{m}$ & $\begin{array}{c}0.321 \\
(4.94)\end{array}$ & 0.970 & 0.0253 & 0.000 & 0.000 \\
\hline
\end{tabular}

Table 6 - Each line reports regression statistics of German linearly detrended per capita output on a constant and on own lags using quarterly data 1925:I to 1938:III. Dependent variable: Lines $1 \& 2$ private output, Lines $3 \& 4$ total output. Coefficient $=$ estimate when variable is added to regression, $\mathrm{SER}=$ standard errors of regression, F-statistic = probability value of the null that the variable is zero, Log-likelihood-ratio $=$ probability value of the null that the variable is zero.

\begin{tabular}{|c|c|c|c|c|c|c|}
\hline \multicolumn{7}{|c|}{ Table 7: Regression results } \\
\hline Line & Variable & $\begin{array}{c}\text { Coefficient } \\
(t \text {-value })\end{array}$ & $\bar{R}^{2}$ & S.E.R. & $\begin{array}{c}\text { F-statistic } \\
\text { (variable })\end{array}$ & $\begin{array}{c}\text { Log likelihood } \\
\text { ratio }\end{array}$ \\
\hline 1 & - & - & 0.938 & 0.0399 & - & - \\
\hline 2 & $\mathrm{y}_{-1}^{m}$ & $\begin{array}{c}0.363 \\
(4.59)\end{array}$ & 0.957 & 0.0334 & 0.000 & 0.000 \\
\hline 3 & $\mathrm{y}_{-1 \text { to }-4}^{m}$ & & 0.960 & 0.0324 & 0.000 & 0.000 \\
\hline 4 & - & - & 0.955 & 0.0311 & - & - \\
\hline 5 & $\mathrm{y}^{m}$ & $\begin{array}{c}0.253 \\
(2.98)\end{array}$ & 0.962 & 0.0288 & 0.005 & 0.002 \\
\hline 6 & $\mathrm{y}_{-1 \text { to }-4}^{m}$ & - & 0.990 & 0.0294 & 0.071 & 0.037 \\
\hline
\end{tabular}

Table 7 - Each line reports regression statistics of German linearly detrended per capita output on a constant and on own lags using quarterly data 1925:I to 1938:III. Dependent variable: Lines 1 to 3 private output, Lines 4 to 6 total output. 


\begin{tabular}{|c|c|c|c|c|c|c|}
\hline \multicolumn{7}{|c|}{ Table 8: Regression results (HP-filter) } \\
\hline Line & Variable & $\begin{array}{c}\text { Coefficient } \\
(t \text {-value })\end{array}$ & $\bar{R}^{2}$ & S.E.R. & $\begin{array}{c}\text { F-statistic } \\
\text { (variable) }\end{array}$ & $\begin{array}{c}\text { Log likelihood } \\
\text { ratio }\end{array}$ \\
\hline 1 & - & - & 0.938 & 0.0399 & - & - \\
\hline 2 & $\mathrm{y}^{m}$ & $\begin{array}{c}0.293 \\
(6.06)\end{array}$ & 0.965 & 0.0300 & 0.000 & 0.000 \\
\hline 3 & - & - & 0.955 & 0.0311 & - & - \\
\hline 4 & $\mathrm{y}^{m}$ & $\begin{array}{c}0.105 \\
(1.91)\end{array}$ & 0.958 & 0.0303 & 0.062 & 0.046 \\
\hline
\end{tabular}

Table 8 - Each line reports regression statistics of German linearly detrended per capita output on a constant and on own lags using quarterly data 1925:I to 1938:III. Dependent variable: Lines $1 \& 2$ private output, Lines $3 \& 4$ total output.

\begin{tabular}{|l|l|l|}
\hline \multicolumn{3}{|c|}{ Table 9: Predictive power of alt. sunspots } \\
\hline Dependent & $\bar{R}^{2}$ or $\Delta \bar{R}^{2}$ & $\begin{array}{c}\text { Significance } \\
(p \text {-value })\end{array}$ \\
\hline $\mathrm{GNP}^{\text {rivate }}$ & 0.320 & 0.000 \\
\hline $\mathrm{GNP}^{\text {total }}$ & 0.163 & 0.013 \\
\hline \hline $\mathrm{GNP}^{\text {rivate }}$ & 0.295 & 0.000 \\
\hline $\mathrm{GNP}^{\text {total }}$ & 0.019 & 0.169 \\
\hline
\end{tabular}

Table 9 - The upper part reports $\bar{R}^{2}$ and the lower one changes in $\bar{R}^{2}$ after sunspots are added to regression. The third column displays probability values of the null that the sunspot variable is zero (log likelihood ratio).

\begin{tabular}{|c|c|c|c|c|c|c|}
\hline \multicolumn{7}{|c|}{ Table 10: Regression results (alt. sunspots) } \\
\hline Line & Variable & $\begin{array}{c}\text { Coefficient } \\
(t \text {-value) }\end{array}$ & $\bar{R}^{2}$ & S.E.R. & $\begin{array}{c}\text { F-statistic } \\
(\text { variable })\end{array}$ & $\begin{array}{c}\text { Log likelihood } \\
\text { ratio }\end{array}$ \\
\hline 1 & - & - & 0.938 & 0.0399 & - & - \\
\hline 2 & $\mathrm{y}^{m}$ & $\begin{array}{c}0.348 \\
(5.75)\end{array}$ & 0.963 & 0.0310 & 0.000 & 0.000 \\
\hline 3 & - & - & 0.955 & 0.0311 & - & - \\
\hline 4 & $\mathrm{y}^{m}$ & $\begin{array}{c}0.263 \\
(3.62)\end{array}$ & 0.965 & 0.0277 & 0.062 & 0.046 \\
\hline
\end{tabular}

Table 10 - Each line reports regression statistics of German linearly detrended per capita output on a constant and on own lags using quarterly data 1925:I to 1938:III. Dependent variable: Lines $1 \& 2$ private output, Lines $3 \& 4$ total output. 


\begin{tabular}{|c|c|c|c|c|c|c|}
\hline \multicolumn{7}{|c|}{ Table 11: Regression results (Supply shocks) } \\
\hline Line & Variable & $\begin{array}{c}\text { Coefficient } \\
(t \text {-value })\end{array}$ & $\bar{R}^{2}$ & S.E.R. & $\begin{array}{c}\text { F-statistic } \\
\text { (variable) }\end{array}$ & $\begin{array}{c}\text { Log likelihood } \\
\text { ratio }\end{array}$ \\
\hline 1 & - & - & 0.938 & 0.0399 & - & - \\
\hline 2 & $\mathrm{y}^{m}$ & $\begin{array}{c}0.145 \\
(2.87)\end{array}$ & 0.946 & 0.0372 & 0.009 & 0.006 \\
\hline 3 & $\mathrm{y}_{-1}^{m}$ & $\begin{array}{c}0.084 \\
(1.49)\end{array}$ & 0.940 & 0.0394 & 0.143 & 0.121 \\
\hline 4 & $\mathrm{y}_{-1 \text { to }-4}^{m}$ & - & 0.941 & 0.0394 & 0.219 & 0.155 \\
\hline
\end{tabular}

Table 11 - Each line reports regression statistics of German linearly detrended per capita private output on a constant and on own lags using quarterly data 1925:I to 1938:III.

\begin{tabular}{|l|l|l|}
\hline \multicolumn{3}{|c|}{ Table 12: Predictive power of sunspots } \\
\hline Dependent & $\bar{R}^{2}$ or $\Delta \bar{R}^{2}$ & $\begin{array}{c}\text { Significance } \\
(p \text {-value })\end{array}$ \\
\hline $\mathrm{GNP}^{\text {private }}$ & 0.127 & 0.031 \\
\hline $\mathrm{GNP}^{\text {total }}$ & 0.185 & 0.008 \\
\hline \hline $\mathrm{GNP}^{\text {private }}$ & 0.104 & 0.030 \\
\hline $\mathrm{GNP}^{\text {total }}$ & 0.143 & 0.004 \\
\hline
\end{tabular}

Table 12 - The upper part reports $\bar{R}^{2}$ and the lower one changes in $\bar{R}^{2}$ after sunspots are added to regression. The third column displays probability values of the null that the sunspot variable is zero (log likelihood ratio).

\begin{tabular}{|c|c|c|c|c|c|c|}
\hline \multicolumn{7}{|c|}{ Table 13: Regression results (alt. employment series) } \\
\hline Line & Variable & $\begin{array}{c}\text { Coefficient } \\
(t \text {-value })\end{array}$ & $\bar{R}^{2}$ & S.E.R. & $\begin{array}{c}\text { F-statistic } \\
(\text { variable })\end{array}$ & $\begin{array}{c}\text { Log likelihood } \\
\text { ratio }\end{array}$ \\
\hline 1 & - & - & 0.938 & 0.0311 & - & - \\
\hline 2 & $\mathrm{y}^{m}$ & $\begin{array}{c}0.495 \\
(2.87)\end{array}$ & 0.963 & 0.0286 & 0.006 & 0.003 \\
\hline 3 & - & - & 0.955 & 0.0399 & - & - \\
\hline 4 & $\mathrm{y}^{m}$ & $\begin{array}{c}0.165 \\
(1.53)\end{array}$ & 0.957 & 0.0307 & 0.133 & 0.108 \\
\hline
\end{tabular}

Table 13 - Reports regression statistics of German linearly detrended per capita output on a constant and own lags using quarterly data 1925:I to 1938:III. Dependent variable: Lines 1 to 3 private output, Lines 4 to 6 total output. 


\begin{tabular}{|c|c|c|c|c|c|c|}
\hline \multicolumn{7}{|c|}{ Table 14: Regression results (alt. reduced form) } \\
\hline Line & Variable & $\begin{array}{c}\text { Coefficient } \\
(t \text {-value })\end{array}$ & $\bar{R}^{2}$ & S.E.R. & $\begin{array}{c}\text { F-statistic } \\
\text { (variable) }\end{array}$ & $\begin{array}{c}\text { Log likelihood } \\
\text { ratio }\end{array}$ \\
\hline 1 & - & - & 0.938 & 0.0399 & - & - \\
\hline 2 & $\mathrm{y}^{m}$ & $\begin{array}{c}0.605 \\
(5.48)\end{array}$ & 0.962 & 0.0315 & 0.000 & 0.000 \\
\hline 3 & - & - & 0.955 & 0.0311 & - & - \\
\hline 4 & $\mathrm{y}^{m}$ & $\begin{array}{c}0.328 \\
(2.44)\end{array}$ & 0.960 & 0.0296 & 0.019 & 0.012 \\
\hline
\end{tabular}

Table 14 - Each line reports regression statistics of German linearly detrended per capita output on a constant and on own lags using quarterly data 1925:I to 1938:III. Dependent variable: Lines $1 \& 2$ private output, Lines $3 \& 4$ total output.

\begin{tabular}{|l|l|l|}
\hline \multicolumn{3}{|c|}{ Table 15: Predictive power of sunspots (Salyer \& Sheffrin) } \\
\hline Dependent & $\bar{R}^{2}$ or $\Delta \bar{R}^{2}$ & $\begin{array}{c}\text { Significance } \\
(p \text {-value })\end{array}$ \\
\hline GNP $^{\text {private }}$ & 0.140 & 0.018 \\
\hline GNP $^{\text {total }}$ & 0.134 & 0.021 \\
\hline \hline GNP $^{\text {private }}$ & 0.103 & 0.026 \\
\hline GNP $^{\text {total }}$ & 0.049 & 0.102 \\
\hline
\end{tabular}

Table 15 - The upper part reports $\bar{R}^{2}$ and the lower one changes in $\bar{R}^{2}$ after sunspots are added to regression. The third column displays probability values of the null that the sunspot variable is zero (log likelihood ratio).

\begin{tabular}{|c|c|c|c|c|c|c|}
\hline \multicolumn{7}{|c|}{ Table 16: Regression results (Salyer \& Sheffrin) } \\
\hline Line & Variable & $\begin{array}{c}\text { Coefficient } \\
(t \text {-value })\end{array}$ & $\bar{R}^{2}$ & S.E.R. & $\begin{array}{c}\text { F-statistic } \\
(\text { variable })\end{array}$ & $\begin{array}{c}\text { Log likelihood } \\
\text { ratio }\end{array}$ \\
\hline 1 & - & - & 0.938 & 0.0311 & - & - \\
\hline 2 & $\mathrm{y}^{m}$ & $\begin{array}{c}0.206 \\
(3.19)\end{array}$ & 0.948 & 0.0366 & 0.003 & 0.001 \\
\hline 3 & - & - & 0.955 & 0.0399 & - & - \\
\hline 4 & $\mathrm{y}^{m}$ & $\begin{array}{c}0.161 \\
(2.64)\end{array}$ & 0.961 & 0.0293 & 0.011 & 0.007 \\
\hline
\end{tabular}

Table 16 - Reports regression statistics of German linearly detrended per capita output on a constant and own lags using quarterly data 1925:I to 1938:III. Dependent variable: Lines 1 to 3 private output, Lines 4 to 6 total output. 